CANCER BIOLOGY

\section{How exercise helps to combat cancer}

Mice that take exercise have fewer tumours than those that do not - thanks to more cancer-fighting immune cells finding their way into tumours.

Studies in humans have linked the effects of taking regular exercise to a reduced risk of developing cancer. To investigate the underlying molecular mechanisms, Pernille Hojman of the University of Copenhagen in Denmark and her colleagues compared tumour growth in sedentary mice and in those that had access to an exercise wheel over four weeks.

Animals that ran had about $60 \%$ fewer tumours, which were also smaller in size. Exercise was associated with an increase in the number of a particular type of immune cell - the natural killer cell - found in the tumours. An exercise-induced surge in the hormone adrenaline mobilized these cells.

Cell Metab. http://doi.org/bcnk (2016)

\section{MATERIALS}

\section{Shells spark strong graphene fibre}

A composite thread with a structure inspired by nacre the iridescent material found inside many seashells - is the strongest graphene-based fibre ever made.

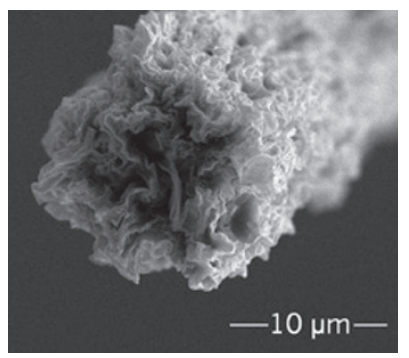

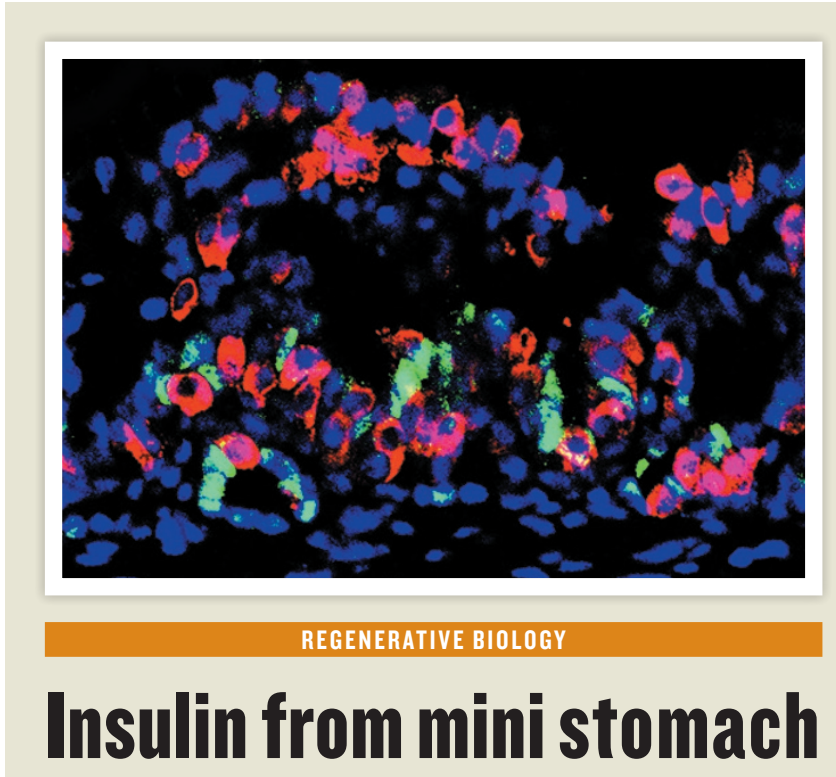

Stomach tissue can be reprogrammed to mimic insulinproducing pancreatic cells and control diabetes when implanted into mice.

A certain type of cell in one part of the stomach has similar gene-expression patterns to $\beta$-cells, which make insulin in the pancreas. Qiao Zhou at Harvard University in Cambridge, Massachusetts, and his colleagues reprogrammed these cells using a mix of key DNA-binding proteins, and found that more than $40 \%$ formed insulin-producing cells. The reprogrammed cells developed into stomach mini-organs (pictured) that, when transplanted into mice lacking $\beta$-cells, prevented spikes in blood sugar levels and kept animals alive for 6 months compared to untreated mice, which died within 8 weeks.

The results suggest that the stomach could serve as a renewable source of $\beta$-cells to treat diabetes, the authors say. Cell Stem Cell http://doi.org/bcqc (2016)

Such fibres are typically produced by spinning together nanometre-thick sheets of graphene oxide. But they often have poor tensile strength, probably owing to weak interactions between the nanosheets. To strengthen the threads, Qunfeng Cheng of Beihang University in Beijing and his colleagues added two more ingredients: calcium ions and a flexible carbon compound called PCDO. These help to bind the nanosheets together, mimicking the strong interactions in nacre. The team produced a fibre roughly 20 micrometres wide (pictured) that could be tied in a knot without fracturing and could support a 2-gram weight.

The fibres also conduct electricity, making them a promising material for flexible electrodes or artificial muscles. Adv. Mater. http://doi.org/f3k23w (2016)

\section{PALAEOECOLOGY \\ Habitats of ancient humans revealed}

Some hominins may have preferred to live in shady glades near fresh water nearly
2 million years ago.

Clayton Magill at the Swiss Federal Institute of Technology in Zurich and his colleagues took samples from a layer of soil in Olduvai Gorge, Tanzania, where fossil remains for early Homo and Paranthropus boisei hominins have been found. This 1.8-million-year-old soil was covered by a layer of volcanic ash, which preserved the distinctive chemical signatures left behind by ancient plants. By analysing these 'biomarkers', the team was able to distinguish aquatic from terrestrial plants, grasses from non-grasses, and woody plants from herbaceous ones.

The biomarker analysis and fossil remains suggest that the hominins favoured a small wooded area near a freshwater wetland, presumably because it offered drinking water, edible plants and shade. The presence of fossilized butchered animal remains also implies that the hominins brought food back to their woodland home from the larger grassland area.

Proc. Natl Acad. Sci. USA http://dx.doi.org/10.1073/ pnas.1507055113 (2016) MICROBIOLOGY

\section{Gut microbes help malnutrition}

Manipulating the gut microbes of undernourished children could help them to gain weight, three laboratory studies in mice and pigs suggest.

Malnourished children can struggle to gain weight even on high-nutrient diets, and studies have suggested that under-nutrition stops their gut microbiomes from maturing. A team led by Jeffrey Gordon at Washington University in St. Louis, Missouri, transplanted gut microbes from undernourished and healthy children from Malawi into germ-free mice, and found 